\title{
Systemic Importance of an Ophthalmic Finding: Hollenhorst Plaques
}

Sashwanthi Mohan, MBBS, DNB, FICO*, Sujatha Mohan, DO, FRCS and Mohan Rajan, DO, $D N B, F R C S$

Rajan Eye Care Hospital, Chennai, India

A 53-year-old woman presented with sudden, painless loss of vision in the left eye and vision of counting fingers. She was a known diabetic and hypertensive on medical management. Left eye retinal examination revealed retinal whitening at the posterior pole along with cherry red spot at the macula and presence of emboli called Hollenhorst plaques in the superotemporal and inferotemporal branches of the retinal arteries (arrows) (Figure 1). Immediate ocular massage was done to dislodge the emboli but visual improvement was minimal. Carotid doppler and a full cardiac work-up was advised which was found to be normal.

Hollenhorst plaques are cholesterol emboli, the most common form of emboli causing branch or central retinal artery occlusions. They are yellow, refractile and originate from carotid or aortic atherosclerotic plaques.

Hollenhorst plaques are important as they can be predictive of an impending ischemic stroke especially in the elderly. Immediate carotid doppler should be ordered in these patients to assess carotid artery stenosis as well as a cardiological work-up. If the lesion is ulcerated and causing

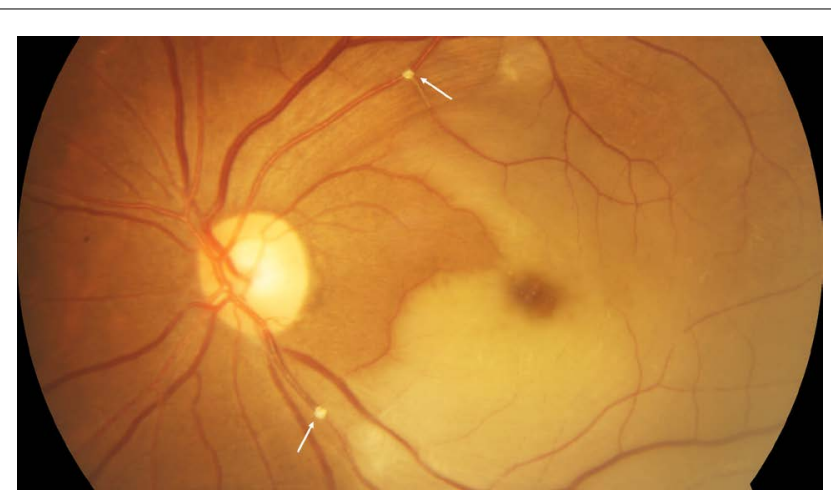

Figure 1: Left eye retinal examination showing retinal whitening with cherry red spot at macula and cholesterol emboli at the superotemporal and inferotemporal branches of the retinal arteries.

more than $70 \%$ stenosis, the patient should be referred for stenting to an interventional radiologist.

\section{Conflicts of Interest}

The authors do not have any financial interest.

\footnotetext{
*Corresponding author: Sashwanthi Mohan, MBBS, DNB, FICO, Rajan Eye Care Hospital, No. 5, Vidyodaya, East $2^{\text {nd }}$ Street, T. Nagar, Chennai - 600017, Tamilnadu, India, Tel: +919003189254 Accepted: June 12, 2021

Published online: June 14, 2021

Citation: Sashwanthi M, Sujatha M, Rajan M (2021) Systemic Importance of an Ophthalmic Finding: Hollenhorst Plaques. J Ophthalmic Res Ocular Care 4(1):77-77
} 